\title{
Statistical Process Control in Conditions of Piece AND SMALl Lot PRODUCTION
}

\author{
Mariusz Kolosowski, Jerzy Duda, Jacek Tomasiak \\ University of Applied Sciences in Nysa,Armii Krajowej 7, Nysa 48-300, Poland
}

\begin{abstract}
The aim of the article is to present the essence of the adaptation of common SPC solutions appropriate for mass and batch production, to the conditions of piece and small lot production on the example of the selected production process. The article presents the possibility of using Shewhart control charts in improving piece and small lot production processes. The principles of data collection and transformation, to be useful to prepare charts, have been pointed out. Moreover, determination of capability indices for piece and small lot production has been shown. The proposed solution of using statistical process control tools in the analyzed company enables the board a fair assessment of the processes from the point of view of quality assurance, and thus reduce the cost of poor quality and well targeted improvement actions.
\end{abstract}

Keywords: quality; SPC; control chart; piece and small lot production; quality improvement
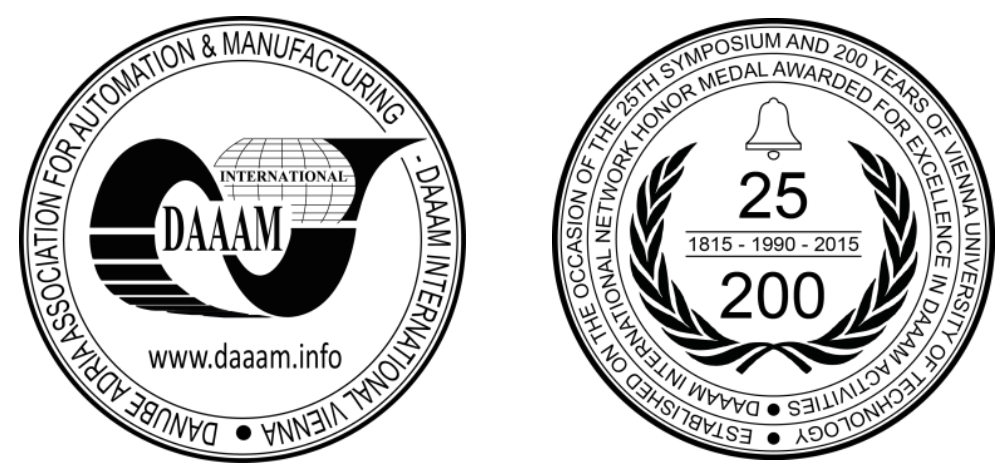

This Publication has to be referred as: Kolosowski, M[ariusz]; Duda, J[erzy] \& Tomasiak, J[acek] (2016). Statistical process control in conditions of piece and small lot production, Proceedings of the 26th DAAAM International Symposium, pp.0147-0155, B. Katalinic (Ed.), Published by DAAAM International, ISBN 978-3-902734-07-5, ISSN 1726-9679, Vienna, Austria DOI:10.2507/26th.daaam.proceedings.021 


\section{Introduction}

Quality - indicating satisfaction and customer satisfaction - is now regarded as the key factor in providing organizations the competitive advantage. The use of innovative manufacturing techniques and continuous cost reduction may be futile if the product is rejected by customers due to failure to meet their expectations.

Now, in conditions of dynamically developing production technologies and increased competition, quality control alone is not able to provide companies stable and unthreatened market position. Quality assurance demands the system approach. It is planning quality and appropriate control of all areas that have an influence on it.

The contemporary concept of quality is based on the principle that prevention causes of bad quality is better than detection and correction. It requires a new approach that quality is not only connected with control and compliance with requirements. Quality should be primarily understood as a supplier's ability to continuous meeting the needs of the customer, both formulated and potential.

Contemporary conditions for business, primarily the increasing competition and the dynamics of change, brought about by the new task of ensuring high-quality products and services, increase the efficiency and effectiveness of business processes while striving to reduce production costs and shorten production cycles. A chance for radical change, manifested primarily to better results, is accurate, ongoing analysis of the processes carried out in the company, their reorganization and continuous improvement $[4,5]$.

Appropriate methods and tools should be selected to allow diagnosis and improvement of the system and the processes. One of the basic methods used in the production practice is statistical process control and processes capability analysis.

Bearing in mind that the success of taken business activities largely depends on the fulfilling of the quality requirements especially in the technical aspects, it was found to define the methodology by which it would be possible to analyze and evaluate the quality of business processes in the enterprise. Research contribution was the company operating in the field of maintenance, which produces, among others, parts individually and in small quantities. The company managers are fully aware that only the correct diagnosis of the existing situation makes it possible to identify the areas which need to be improved. This is not possible without using properly selected methods and tools specific to the organization. Analysis of literature shows general issues and ideas in SPC [8, 20, 21], practical examples of the use of selected SPC methods and tools in conditions of mass and batch production $[1,2,10,18,19]$ or own SPC tools and models proposals $[3,7,9,14]$. Yet, it is difficult to find examples relating to the piece and small lot production, especially based on adapting conventional SPC tools. The issue is so important that a company cannot determine the quality of processes and ability without the right tools to control them, and that's why it runs the risk of high costs due to internal and external failures, which prevents the business success.

\section{Processes variability. Statistical process control}

As J. Oakland states, the responsibility for quality in any transformation process must lie with the operators of the process - the producers. To fulfill this responsibility people must be provided with tools necessary to [16]:

- know if the process is capable of meeting requirements,

- know if the process is meeting requirements at any time,

- make correct adjustments to the process or its inputs when it is not meeting the requirements.

From the point of view of processes quality in the enterprise, understanding the essence of variability is extremely important. It is one of the best tools which a company can use. It allows streamlining the organization and creates opportunities for its continuous improvement. Lack of understanding of the variability contributes to [6]:

- making bad decisions and actions,

- $\quad$ seeing trends and tendencies where they do not exist,

- presenting the natural variability as an event of special importance,

- punishing and rewarding employees for things over which they have no influence,

- lack of understanding of the company, the manufacturing process etc.,

- inability to predict correctly and make plans for the future,

- limited ability to carry out improvements.

Walter Shewhart identified two kinds of variability $[12,15]$ :

- controlled variation - variation that is characterized by a stable and consistent pattern of variation over time. This type of variation will be random in nature and will be exhibited by a uniform fluctuation about a constant level,

- uncontrolled variation - variation that is characterized by a pattern of variation that changes over time and hence is unpredictable. This type of variation will typically contain some structure. 
According to the process variation Walter Shewhart specified two causes of variability:

- $\quad$ common (natural) causes - usual, historical, quantifiable variation in a system.

- $\quad$ special (assignable) causes - unusual, not previously observed, non-quantifiable variation.

Shewhart's discovery appeared to be a milestone in reducing variability. If the process variability is large, then you cannot predict what will be the next product like, or what will happen over time. From the point of view of the quality assurance system, such a situation is unacceptable and has become a cause of the development of statistical process control SPC.

SPC is a method that allows to monitor and predict the state of the process, as well as overseeing the individual components of the production process, such as machines, technological equipment or measuring apparatus.

Undesirable state of random variation results from:

- improper handling and maintenance of equipment,

- wrong choice of equipment to the required degree of precision,

- bad quality of production tools,

- bad quality of the measurement equipment,

- defective or unsuitable material.

- disorder, noise, vibration, inappropriate temperature, improper lighting, etc.

The most important special, assignable causes of variation are:

- change of the quality of the raw material,

- tiredness of the operator,

- change of the measuring equipment,

- wear of the tool,

- not calibrated measuring equipment, etc.

A typical algorithm of the SPC implementation may be described as follows:

1. Stabilizing the process by identifying and eliminating the assignable causes of variability (application of Shewhart control charts).

2. Determining the process capability to require the internal or external customers ( $\mathrm{Cp}$ and $\mathrm{Cpk}$ indexes).

3. In case of insufficient process capability - improving the process by reducing its natural variability.

4. Maintaining a capable and stable process by identifying and removing the special causes.

5. Periodic analysis of the process capability to its continuous improvement (and then return to the step 4).

\section{The proposal of SPC for piece and small lot production}

The proposal to implement the SPC methods in the analyzed enterprise covers:

1. Selection of the key parameter (parameters) for the final product quality.

2. Construction of the histogram for the approximate verification of the random variable.

3. The assessment of the process stability using the Shewhart $x^{-}-\mathrm{R}$ chart.

4. The process capability analysis using $\mathrm{Cp}$ and $\mathrm{Cpk}$ indexes.

For the purpose of implementing the concept of the SPC in the analyzed company the data input sheet was proposed (Table 1). The sheet allows to transform data for piece and small lot production in accordance with following formulas (1), (2), (3):

- transformation of the upper specification limit USL:

$\mathrm{USL} \Rightarrow \mathrm{USLt}=1$

- transformation of the lower specification limit LSL:

$\mathrm{LSL} \Rightarrow \mathrm{LSLt}=0$

- transformation of the analyzed parameter values P:

$\mathrm{P} \Rightarrow P_{t}=\frac{P-L S L}{U S L-L S L}$ 


\begin{tabular}{|c|c|c|c|c|c|c|c|c|c|c|c|c|}
\hline \multirow{2}{*}{$\begin{array}{l}\text { Number } \\
\text { of } \\
\text { sample }\end{array}$} & \multicolumn{4}{|c|}{ Measurements in sample } & \multicolumn{4}{|c|}{$\begin{array}{l}\text { Measurements after } \\
\text { transformation }\end{array}$} & \multirow{2}{*}{$\begin{array}{r}\text { sample } \\
\text { mean } \bar{x}\end{array}$} & \multirow{2}{*}{$\begin{array}{c}\text { sample } \\
\text { range } \\
\text { R }\end{array}$} & \multirow[t]{2}{*}{$\begin{array}{l}\text { Control limits } \\
\text { for } \mathrm{R} \text { chart }\end{array}$} & \multirow{2}{*}{$\begin{array}{c}\begin{array}{c}\text { Control limits } \\
\text { for }\end{array} \text { chart } \\
\ldots\end{array}$} \\
\hline & 1 & 2 & 3 & 4 & 1 & 2 & 3 & 4 & & & & \\
\hline \multicolumn{13}{|l|}{1} \\
\hline \multicolumn{13}{|l|}{2} \\
\hline \multicolumn{13}{|l|}{3} \\
\hline \multicolumn{13}{|l|}{4} \\
\hline \multicolumn{13}{|l|}{5} \\
\hline \multicolumn{13}{|l|}{$\ldots$} \\
\hline $\mathrm{n}$ & & & & & & & & & & & & \\
\hline
\end{tabular}

Table 1. Data input sheet - piece and small lot production

Parameters for the control charts (central lines, control lines, warning lines) are determined basis on the formulas in chapter 4. A2, D3 i D4 are sample size-specific anti-biasing constants. After entering the data all lines are generated automatically and control charts are created. In addition, the values of $C_{p}$ and $C_{p k}$ indices are determined. The indices are the base for the process capability assessment.

\section{Practical example}

The analyzed process concerns the production of the sliding quill, but manufactured in small batches and characterized by different geometrical parameters. The use of SPC tools is presented for the geometry parameter, which is the inner diameter of the quill. It is one of the key parameters of the quality of the final product.

The first step was to collect data. Therefore, the diameters of 60 pieces divided into 15 samples of size 4 were measured. The first five samples of measurements come from the quill with the inner diameter $\emptyset 57_{-0,3}^{-0,2}$ (Fig. 1), another five $\emptyset 45_{-0,3}^{-0,2}$, and the last five $\emptyset 35_{-0,3}^{-0,2}$ (Table 2).

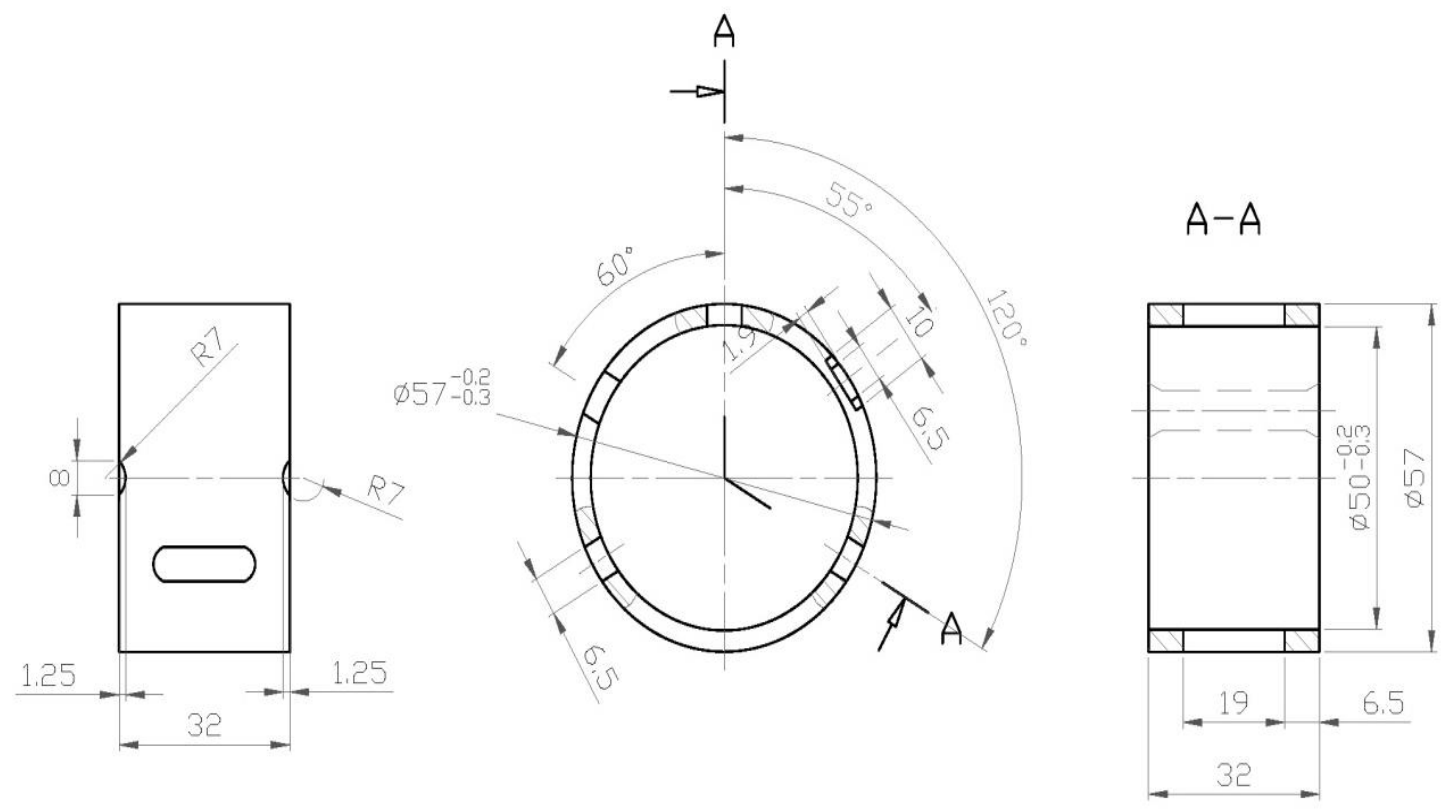

Fig. 1. Analyzed product - sliding quill

\begin{tabular}{ccccc}
\hline \multirow{2}{*}{ Number of sample } & \multicolumn{4}{c}{ Measurements in sample } \\
\cline { 2 - 5 } & $\mathbf{1}$ & $\mathbf{2}$ & $\mathbf{3}$ & $\mathbf{4}$ \\
\hline $\mathbf{1}$ & 56,75 & 56,74 & 56,75 & 56,74 \\
\hline $\mathbf{2}$ & 56,74 & 56,75 & 56,72 & 56,75 \\
\hline $\mathbf{3}$ & 56,76 & 56,74 & 56,77 & 56,74 \\
\hline $\mathbf{4}$ & 56,75 & 56,73 & 56,75 & 56,73 \\
\hline $\mathbf{5}$ & 56,76 & 56,72 & 56,74 & 56,75 \\
\hline $\mathbf{6}$ & 44,75 & 44,73 & 44,73 & 44,76 \\
\hline $\mathbf{7}$ & 44,76 & 44,76 & 44,75 & 44,74 \\
\hline $\mathbf{8}$ & 44,76 & 44,78 & 44,76 & 44,74 \\
\hline
\end{tabular}




\begin{tabular}{ccccc}
\hline $\mathbf{9}$ & 44,74 & 44,75 & 44,77 & 44,75 \\
\hline $\mathbf{1 0}$ & 44,76 & 44,73 & 44,74 & 44,73 \\
\hline $\mathbf{1 1}$ & 34,74 & 34,72 & 34,75 & 34,74 \\
\hline $\mathbf{1 2}$ & 34,74 & 34,75 & 34,77 & 34,78 \\
\hline $\mathbf{1 3}$ & 34,77 & 34,74 & 34,75 & 34,73 \\
\hline $\mathbf{1 4}$ & 34,76 & 34,77 & 34,76 & 34,74 \\
\hline $\mathbf{1 5}$ & 34,74 & 34,76 & 34,73 & 34,77 \\
\hline
\end{tabular}

Table 2. Measurement data

Due to the fact that we are dealing with similar products, but still characterized by different values of analyzed geometric parameter, using traditional SPC tools (histogram, Shewhart control charts) and counting capability indexes on the basis of these data would not make any sense. Therefore, the procedure of data transformation was carried out first. Proposed transformation is based on the formulas (1), (2), (3). The data from the Table 2 after the transformation according to the proposed model is presented in the Table 3.

\begin{tabular}{ccccc}
\hline \multirow{2}{*}{ Number of sample } & \multicolumn{5}{c}{ Measurements in sample } \\
\cline { 2 - 5 } & $\mathbf{1}$ & $\mathbf{2}$ & $\mathbf{3}$ & $\mathbf{4}$ \\
\hline $\mathbf{1}$ & 0,5 & 0,4 & 0,5 & 0,4 \\
\hline $\mathbf{2}$ & 0,4 & 0,5 & 0,2 & 0,5 \\
\hline $\mathbf{3}$ & 0,6 & 0,4 & 0,7 & 0,4 \\
\hline $\mathbf{4}$ & 0,5 & 0,3 & 0,5 & 0,3 \\
\hline $\mathbf{5}$ & 0,6 & 0,2 & 0,4 & 0,5 \\
\hline $\mathbf{6}$ & 0,5 & 0,3 & 0,3 & 0,6 \\
\hline $\mathbf{7}$ & 0,6 & 0,6 & 0,5 & 0,4 \\
\hline $\mathbf{8}$ & 0,6 & 0,8 & 0,6 & 0,4 \\
\hline $\mathbf{9}$ & 0,4 & 0,5 & 0,7 & 0,5 \\
\hline $\mathbf{1 0}$ & 0,6 & 0,3 & 0,4 & 0,3 \\
\hline $\mathbf{1 1}$ & 0,4 & 0,2 & 0,5 & 0,4 \\
\hline $\mathbf{1 2}$ & 0,4 & 0,5 & 0,7 & 0,8 \\
\hline $\mathbf{1 3}$ & 0,7 & 0,4 & 0,5 & 0,3 \\
\hline $\mathbf{1 4}$ & 0,6 & 0,7 & 0,6 & 0,4 \\
\hline $\mathbf{1 5}$ & 0,4 & 0,6 & 0,3 & 0,7 \\
\hline
\end{tabular}

Table 3. Measurement data after transformation

For the data from the Table 3 the histogram was constructed for the approximate verification of the random variable (Fig. 2).

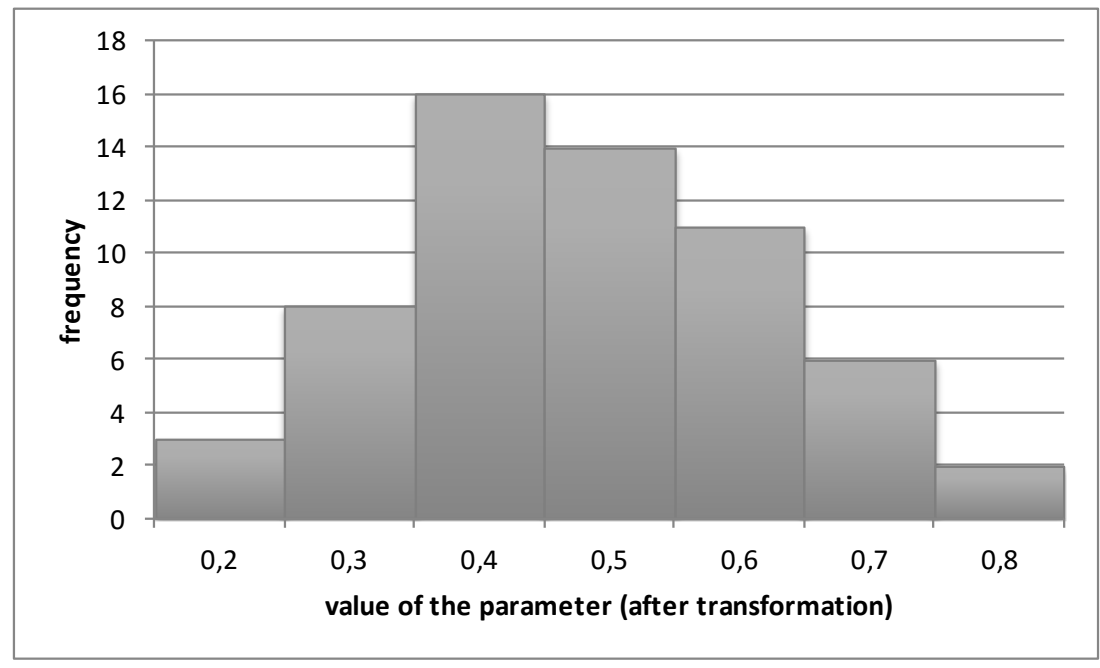

Fig. 2. Histogram

Evaluating the histogram it can be concluded that the analyzed characteristics of the distribution is close to normal distribution. However, the assessment of stability of the process was performed with Shewhart control charts. 
Calculation for the limits for $\bar{x}-R$ chart:

a) R (range) chart:

- $D_{3}$ i $D_{4}$ constants for $\mathrm{n}=4$ :

$$
\begin{aligned}
& D_{3}=0 \\
& D_{4}=2,282
\end{aligned}
$$

- center line $R_{c}$ :

$$
R_{c}=\bar{R}=\frac{1}{15} \sum_{i-1}^{15} R_{i}=0,307
$$

- upper control limit UCL:

$$
U C L=D_{4} \bar{R} \approx 0,700
$$

- lower control limit LCL:

$$
L C L=D_{3} \bar{R}=0
$$

b) $\bar{x}$ (mean) chart:

- $A_{2}$ constant for $\mathrm{n}=4$ :

$$
A_{2}=0,729
$$

- center line $x_{c}$ :

$$
x_{c}=\bar{x}=\frac{1}{15} \sum_{i=1}^{15} \bar{x}_{i}=0,480
$$

- upper control limit UCL:

$$
U C L=x_{c}+A_{2} \bar{R} \approx 0,704
$$

- lower control limit LCL:

$$
L C L=x_{c}-A_{2} \bar{R} \approx 0,256
$$

- upper warning limit UWL:

$$
U W L=x_{c}+\frac{2}{3} A_{2} \bar{R} \approx 0,629
$$

- lower warning limit LWL:

$$
L W L=x_{c}-\frac{2}{3} A_{2} \bar{R} \approx 0,331
$$

The resulting graphs of control charts are shown in the Fig. 3 and Fig. 4. 


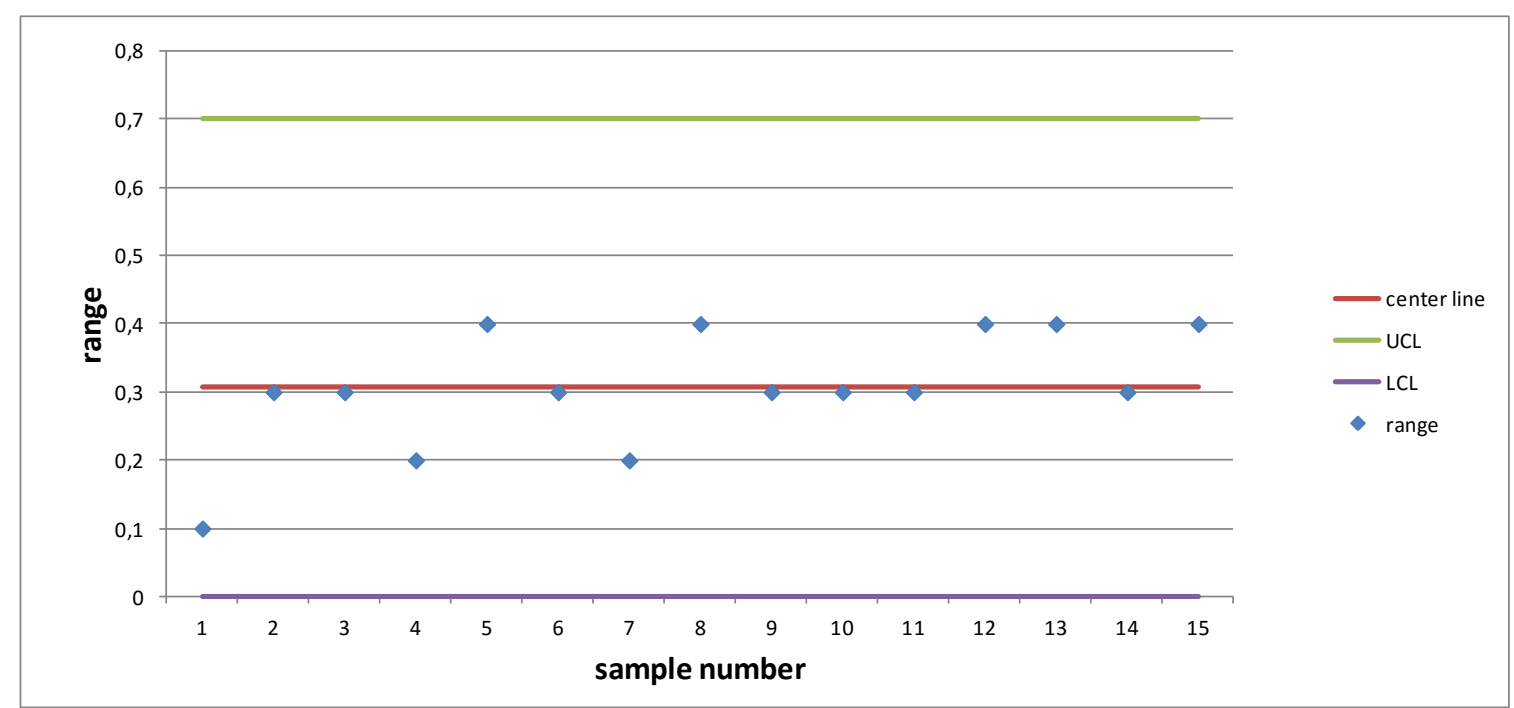

Fig. 3. R (range) chart

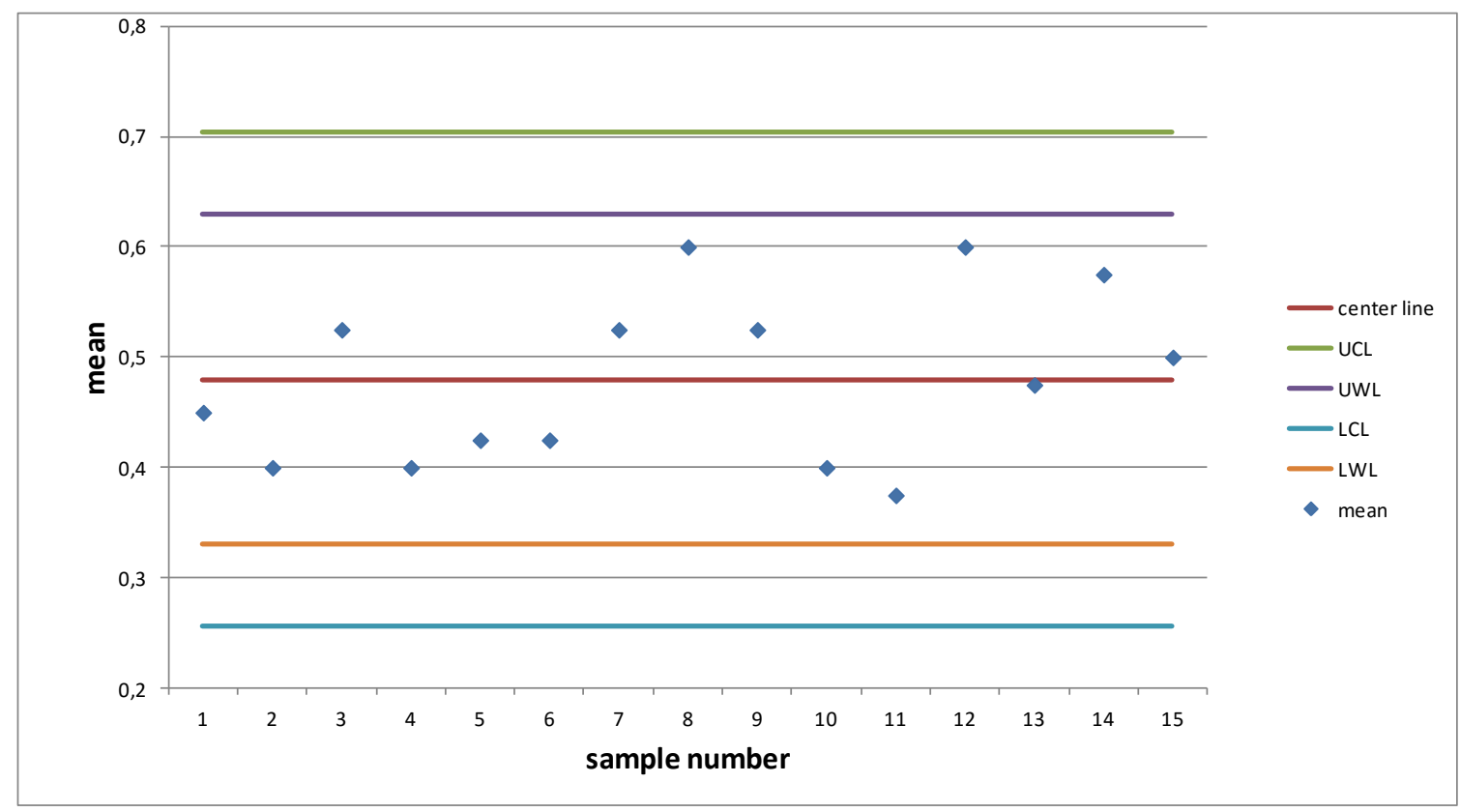

Fig. 4. $\bar{x}$ (mean) chart

Analyzing the charts it may be concluded that the process is stable, therefore, it is in statistical control. There are no out of control signals (Nelson's patterns) noticed in the charts [11, 17]. It is reasonable to conclude that no special (assignable) causes influence the process.

According to the SPC algorithm, the next step was to determine the process capability. To determine capability indexes the following data was used:

$$
\begin{aligned}
& \text { upper specification limit USL (transformed) } \quad-\quad 1 \\
& \text { lower specification limit LSL (transformed) } \quad-\quad 0 \\
& \sigma \quad-0,146 \\
& \mu \quad-0,480 .
\end{aligned}
$$

The resulting value of the $\mathrm{C}_{\mathrm{p}}$ index:

$$
C_{p}=\frac{1}{6 * 0,146} \approx 1,14
$$


The resulting value of the $\mathrm{C}_{\mathrm{pk}}$ index:

$$
C_{p k}=\min \left(\frac{0,480-0}{3 * 0,146} ; \frac{1-0,480}{3 * 0,146}\right) \approx \min (1,10 ; 1,19) \approx 1,10
$$

Analyzing the obtained values of indexes, we can conclude that the process capability is good. It could be slightly improved if the obtained mean value was located exactly in the middle of the tolerance. Good quality confirms the ability of the low probability of obtaining a product of inconsistent quality (from the standpoint of the analyzed properties):

$$
1-P(0 \leq X \leq 1)=P(-3,29 \leq X \leq 3,56) \approx 0,00068
$$

It is necessary to state that the process capability assessment may be different depending on the customer requirements. It is often assumed that processes with higher capability indexes, e.g. 1,5 and more, are considered to be of good quality.

\section{Conclusion}

The research problem was to propose statistical process control tools adopted to the conditions of piece and small lot production, dedicated to the selected company. The presented solutions - control charts and capability indexes - give a fair assessment of the processes from the point of view of quality assurance, and thus reduce the cost of poor quality and well targeted improvement actions. Particularly important is to adapt the commonly used solutions appropriate for mass and batch production to the conditions of piece and small lot production. Pointing the advantages of the proposed solutions it should be emphasized that even with short-run SPC methods are focused on the process and not on the individual units or batches. A variety of products with different nominal value of any parameter may be manufactured in the process carried out under certain conditions, but a process is analyzed with SPC tools, not production batches or units. Thus, the control chart for short batches is none other than monitoring on one chart the process, for which we have to deal interchangeably with more short-run.

Knowledge of the essence of the variability of processes and thorough evaluation of this variability by using the proposed tools allows to streamline the organization, and in fact it creates opportunities for continues improvement. This way we prevent making bad decisions and actions resulting from improper diagnosis of the state of the system. This obviously increases the possibility of correct prediction and making plans for the future, and the ability to deal with improvements. It is clear that the identification of special, assignable causes of variability requires adequate knowledge and experience related to the specificity of a particular process. However, the proposed solution makes it possible to determine whether such causes exist in the system and whether it is appropriate to identify and eliminate them.

Plans for the future are focused on proposals of SPC tools for all key business processes from the quality assurance point of view in the company. Yet, as D. Noskievicova, A. Pauchova and M. Kelblerova [13] indicate, the process improvement with SPC tools is affected by many technical, statistical, methodical, social and economical factors. That is why SPC must be built as a complex problem-solving and long-range process.

\section{References}

[1] M. Al-Salti, A. Statham, A review of the literature on the use of SPC in batch production, Quality and Reliability Engineering International, vol. 10, issue 1 (1994) 49-61.

[2] A. Güllü, A.R. Motorcu, Elimination of the quality problems encountered in mass production by using statistical quality control, Turkish Journal of Engineering and Environmental Sciences, vol. 27, issue 2 (2003) 83-93.

[3] L. Jaupi, Ph. Durand, D. Ghorbanzadeh, Statistical process control methods for individual observations, Lecture Notes in Engineering and Computer Science, vol. 2217, issue 1 (2015) 29-33.

[4] M. Kolosowski, P. Chwastyk, Economic aspects of company processes improvement, 24th International DAAAM Symposium on Intelligent Manufacturing and Automation, Procedia Engineering, Elsevier Publishing Ltd., vol. 69 (2014) 222-230.

[5] M. Kolosowski, A. Kucinska-Landwójtowicz, The use of selected Shewhart control charts in the assessment of logistics processes (in Polish: Wykorzystanie wybranych kart kontrolnych Shewharta w ocenie procesów logistycznych), Logistics (in Polish: Logistyka), 3 (2015) 2230-2240.

[6] J. Koronacki, Statistics in total quality management (in Polish: Statystyka w kompleksowym zarządzaniu jakością), http://www.statsoft.pl/Portals/0/Downloads/Statystyka_w_kompleksowym_Koronacki.pdf, access 28.09.2015.

[7] A.L. Korzenowski, G. Vidor, G.L.R. Vaccaro, C.S. Ten Caten, Control charts for flexible and multi-variety production systems, Computers \& Industrial Engineering, vol. 88 (2015) 284-292. 
[8] S.A.H. Lim, J. Antony, J.A. Garza-Reyes, N. Arshed, Towards a conceptual roadmap for statistical process control implementation in the food industry, Trends in Food Science \& Technology, vol. 44, issue 1 (2015) 117-129.

[9] P.A. Marques, C.B. Cardeira, P. Paranhos, S. Ribeiro, H. Gouveia, Selection of the most suitable statistical process control approach for short production runs: a decision-model, International Journal of Information and Education Technology, vol. 5, issue 4 (2015) 303-310.

[10] A.R. Motorcu, A. Güllü, Statistical process control in machining, a case study for machine tool capability and process capability, Materials and Design, vol. 27, issue 5 (2006) 364-372.

[11] L.S. Nelson, The Shewhart control chart - Tests for special causes, Technical Aids, Journal of Quality Technology, 16 (1984) 238-239.

[12] W. Nierzwicki (Ed.), Quality management. Selected issues, (in Polish: Zarzadzanie jakoscia. Wybrane zagadnienia) Osrodek Doradztwa i Doskonalenia Kadr Sp. z o.o., Gdansk, 1999.

[13] D. Noskievicova, A. Pauchova, M. Kelblerova, Analysis of effective implementation of SPC, Annals of DAAAM for 2011 \& Proceedings of the 22nd International DAAAM Symposium, vol. 22, no. 1, ISSN 1726-9679, ISBN 978-3-901509-83-4, pp. 173, Editor B. Katalinic, Published by DAAAM International, Vienna, Austria, 2011.

[14] D. Noskievicova, B. Woska, Design of methodology for application of statistical control on short run processes in metallurgy, Metalurgija, vol. 53, issue 1 (2013) 81-84.

[15] J.S. Oakland, Statistical Process Control, Routledge, London - New York, 2011.

[16] J.S. Oakland, Total Quality Management, Butterworth Heinemann, New York, 1992.

[17] PN-ISO 8258:1996P - Shewhart control charts (in Polish: Karty kontrolne Shewharta), Polish Committee for Standardization, Warsaw, 1996.

[18] M. Pribytkova, I. Polyantchikov, T. Karaulova, Influence of variability on a reliable production process, Annals of DAAAM for 2010 \& Proceedings of the 21st International DAAAM Symposium, vol. 21, no. 1, ISSN 1726-9679, ISBN 978-3-901509-73-5, Editor B. Katalinic, Published by DAAAM International, Vienna, Austria, 2010.

[19] I.D. Tent, C.D. Dumitrescu, N. Trandafir, Statistical quality control methods of products and services, Annals of DAAAM for 2010 \& Proceedings of the 21st International DAAAM Symposium, vol. 21, no. 1, ISSN 1726-9679, ISBN 978-3-901509-73-5, Editor B. Katalinic, Published by DAAAM International, Vienna, Austria, 2010.

[20] W.H. Woodall, Controversies and contradictions in statistical process control, Journal of QualityTechnology, vol. 32, no. 4, (2000) 341-350.

[21] W.H. Woodall, D.C. Montgomery, Research issues and ideas in statistical process control, Journal of QualityTechnology, vol. 31, no. 4, (1999) 376-386. 